\title{
MORFOLOGIA DE LEITO E PROCESSOS EROSIVO- DEPOSICIONAIS EM ÁREAS AFETADAS POR ACUMULAÇÕES DE DETRITOS LENHOSOS: RIO GUABIROBA, GUARAPUAVA/PR ${ }^{1}$
}

\author{
Andrey Luis Binda \\ Colegiado de Geografia - Universidade Federal da Fronteira Sul (UFFS) - Avenida Fernando Machado, 108E, Centro - \\ Chapecó-SC - CEP89.802-112 - e-mail: abinda@uffs.edu.br
}

Oscar Vicente Quinonez Fernandez.

Colegiado de Geografia - Grupo Multidisciplinar de Estudos Ambientais (GEA) - Universidade Estadual do Oeste do Paraná (UNIOESTE) - Rua Pernambuco, 1777, Centro - Marechal Cândido Rondon-PR - CEP 85.960-000 -

e-mail:fernandez@unioeste.br

\begin{abstract}
Resumo
Os detritos lenhosos desempenham função chave na ecologia e geomorfologia de canais, podendo afetar os processos do canal em um amplo alcance: desde a rugosidade hidráulica, retenção e grânulometria dos sedimentos de leito, até a criação de degraus e depressões, podendo, às vezes, controlar o padrão do canal e a distância/variação de feições fluviais que são fundamentais para a formação de habitat aquáticos. Num contexto desses, a presente pesquisa teve como objetivo verificar a influência de acumulações de detritos lenhosos sobre a morfologia de leito no Rio Guabiroba, município de Guarapuava, mesorregião Centro-Sul do Paraná. As técnicas utilizadas incluíram a instalação de seções de monitoramento batimétrico e elaboração de blocos 3D mediante técnicas de geoprocessamento. O monitoramento foi realizado ao longo de 15 meses (dezembro de 2007 a março de 2009) em três pontos localizados no curso principal do rio. Os resultados indicam a ocorrência de sedimentação na segunda e quinta campanhas e processos de erosão na terceira e quarta campanhas. Esses processos erosivo-deposicionais podem, em parte, ser atribuídos ao regime pluviométrico, com os períodos de alta concentração de chuvas vinculados à erosão do leito e períodos de chuvas escassas e não concentradas relacionadas com a deposição de sedimentos.
\end{abstract}

Palavras-chave: Detritos lenhosos; morfologia de leito; processos erosivo-deposicionais; geomorfologia fluvial.

\begin{abstract}
The wood debris play a key function in the ecology and geomorphology of channels, being able to affect the processes of the channels in an ample reach: since the hydraulic roughness, retention and sized grain of bed sediments, until the creation of steps and pools, being able to the times to control the standard of the channel and distance and variation of fluvial features that are basic for the formation of aquatic habitat. In this context, the present research had as objective, to verify the influence of accumulations of wood debris on the bed morphology in the Guabiroba River, Guarapuava, Center-South of the Parana. The used techniques had included the installation of sections of batimetric measurement and elaboration of 3D blocks by means of geoprocessing techniques. The measurement was carried throughout 15 months (December of 2007 the March of 2009) in three sections located in the main course of the river. The results indicate the occurrence of sedimentation in the second and fifth measurement and processes of erosion in the third and fourth measurement. These processes erosive-depositional can in part be attributed to the pluviometric regime, with the periods of high entailed concentration of rains to the erosion of the stream bed and periods of related scarce and not concentrated rains with the deposition of sediments.
\end{abstract}

Keywords: Wood debris; bed morphology; erosive-depositional processes; fluvial geomorphology.

\footnotetext{
${ }^{1}$ Parte da dissertação de mestrado em Geografia (UNIOESTE-FBE) intitulada: "A influência de detritos lenhosos na morfologia e na sedimentologia de leito no Rio Guabiroba, Guarapuava/PR".
} 


\section{Introdução}

Os rios são considerados os principais agentes geomorfológicos. Essa ação de destaque dos rios decorre não somente da sua ampla distribuição, mas também da sua habilidade em transportar materiais sedimentares oriundos das vertentes, condicionando a evolução da paisagem. Essa carga sedimentar, por sua vez, dependendo da competência e da capacidade de transporte do fluxo, pode ser transportada à jusante ou formar diferentes tipos de depósitos dentro do canal ou em suas margens e planície de inundação (CHRISTOFOLETTI, 1981; SUGUIO \& BIGARELLA, 1990).

A dinâmica de transporte, deposição e erosão no canal é comandada pela distribuição da tensão de cisalhamento (shear stress) no leito. Muitas variáveis, coletivamente denominadas de rugosidade, podem influenciar essa distribuição (LEOPOLD et alii, 1964). A rugosidade do canal exerce resistência ao fluxo e pode ser atribuída a diversos elementos como granulometria e formas do leito, vegetação subaquática e detritos lenhosos (wood debris). Estes últimos correspondem a troncos, galhos e folhas caídos dentro do canal (PIÉGAY \& GURNELL, 1997) e de ocorrência natural em sistemas fluviais que cortam áreas florestadas (DOWNS \& SIMON, 2001).

Os detritos lenhosos desempenham função chave na ecologia e na geomorfologia de canais (MARCUS et alii, 2002), podendo afetar os processos do canal em um amplo espectro: desde a rugosidade hidráulica, a retenção e a textura dos sedimentos do leito (BRUMMER et alii, 2006) até a criação de degraus/soleiras e de depressões, podendo também controlar o padrão do canal (MONTGOMERY \& PIÉGAY, 2003) e a distribuição espacial das feições fluviais (DOWNS \& SIMON, 2001). Também são fundamentais para a formação de habitats aquáticos e como fonte de alimento para peixes e outros animais (MARCUS et alii, 2002; LIMA \& ZAKIA, 2004; WOOSTER \& HILTON, 2004; MUTZ et alii, 2006; YOUNG et alii, 2006).

$\mathrm{Na}$ maioria dos canais naturais, os detritos lenhosos têm significativa influência sobre os processos erosivodeposicionais no canal, determinando a geometria do leito, a morfologia da seção transversal, a sinuosidade e as formas de fundo de vale (MUTZ et alii, 2006). Assim, uma vez dentro de canais, os detritos podem afetar os processos de erosão e de deposição que localmente controlam a geometria do canal, o desenvolvimento e o rompimento de colos de meandros, a formação de barras e o armazenamento de sedimentos (KELLER \& SWANSON, 1979).

Entretanto, o crescimento de atividades econômicas em locais próximos aos canais fluviais reduziu a quantidade de detritos lenhosos nos sistemas fluviais, seja por meio da remoção direta, como pelo desmatamento das florestas ripárias (MONTGOMERY \& ABBE, 2006). Lima \& Zakia (2004) ressaltam que esses materiais deveriam ser mantidos dentro dos canais, de modo a cumprir sua função geomorfológica e biológica (fonte nutricional para a biota aquática) (MARCUS et alii, 2002).

Atualmente, a preservação dos corredores ripários tem sido muito discutida em todo o mundo. Muitos estudos têm buscado demonstrar que os detritos lenhosos são importantes componentes dos ecossistemas ripários, de modo a dirigir esforços para reabilitar não somente as florestas ciliares, mas também os próprios canais, mediante a adição de detritos lenhosos artificiais (CURRAN \& WOHL, 2003).

Entretanto, deve-se enfatizar que estudos relacionados com tal temática são praticamente inexistentes no cenário nacional, havendo a necessidade de pesquisas voltadas aos detalhamentos nos ambientes tropicais e subtropicais do Brasil. Isso demonstra a existência de uma grande diversidade de espécies vegetais e, assim, diferentes variáveis no volume de aporte de detritos lenhosos, na tipologia dos materiais e suas diferentes suscetibilidades à decomposição, fatores que, consequentemente, geram uma multiplicidade de condições e determinam variadas estruturas e tempos de permanência das acumulações. Essa variedade de condições precisa ser melhor entendida para que as implicações sobre a morfologia fluvial nesses ambientes sejam esclarecidas.

Assim, a presente pesquisa tem como objetivo principal verificar a influência de acumulações de detritos lenhosos na morfologia de leito no Rio Guabiroba, em Guarapuava/ PR. Os dados e a interpretação apresentados neste trabalho constituem parte da dissertação de mestrado apresentada por Binda (2009a).

\section{Materiais, métodos e técnicas}

O levantamento batimétrico nas seções de monitoramento foi realizado adotando-se a metodologia empregada por Fernandez (2003), que consiste na delimitação de um polígono no canal, dentro do qual são realizadas as medidas de profundidade a vau em intervalos definidos (Figura 1). Após a identificação e a classificação dos segmentos com expressivas acumulações de detritos lenhosos procedeu-se à definição dos polígonos referentes às seções de monitoramento batimétrico examinadas neste estudo.

O polígono foi inicialmente delimitado por estacas, fortemente fixadas no leito do canal, de modo a contemplar setores a montante e a jusante das acumulações de detritos lenhosos. Assim foi possível avaliar a influência das obstruções nas unidades do canal imediatamente adjacentes. Os tamanhos dos polígonos variaram entre 6,4 a $11,80 \mathrm{~m}$ de comprimento (eixo y) e 2,40 a $7,40 \mathrm{~m}$ de largura (eixo $\mathrm{x}$ ).

As medidas foram tomadas esticando-se firmemente uma corda de nylon ligando os dois pontos do eixo $\mathrm{x}$ (vértices do polígono). Esta corda foi graduada com pontos distan- 
ciados a cada $20 \mathrm{~cm}$. A localização dos pontos de medição foi definida com a utilização de uma corda móvel, também graduada a intervalos de $20 \mathrm{~cm}$ (eixo y) amarrada em ambos os lados das cordas fixas (eixo $\mathrm{x}$ ) formando assim, um con- junto de coordenadas cartesianas (Figura 1). Cada vez que a corda móvel era movimentada, iniciava-se um novo perfil. A medição da profundidade foi realizada com o auxílio de uma régua.

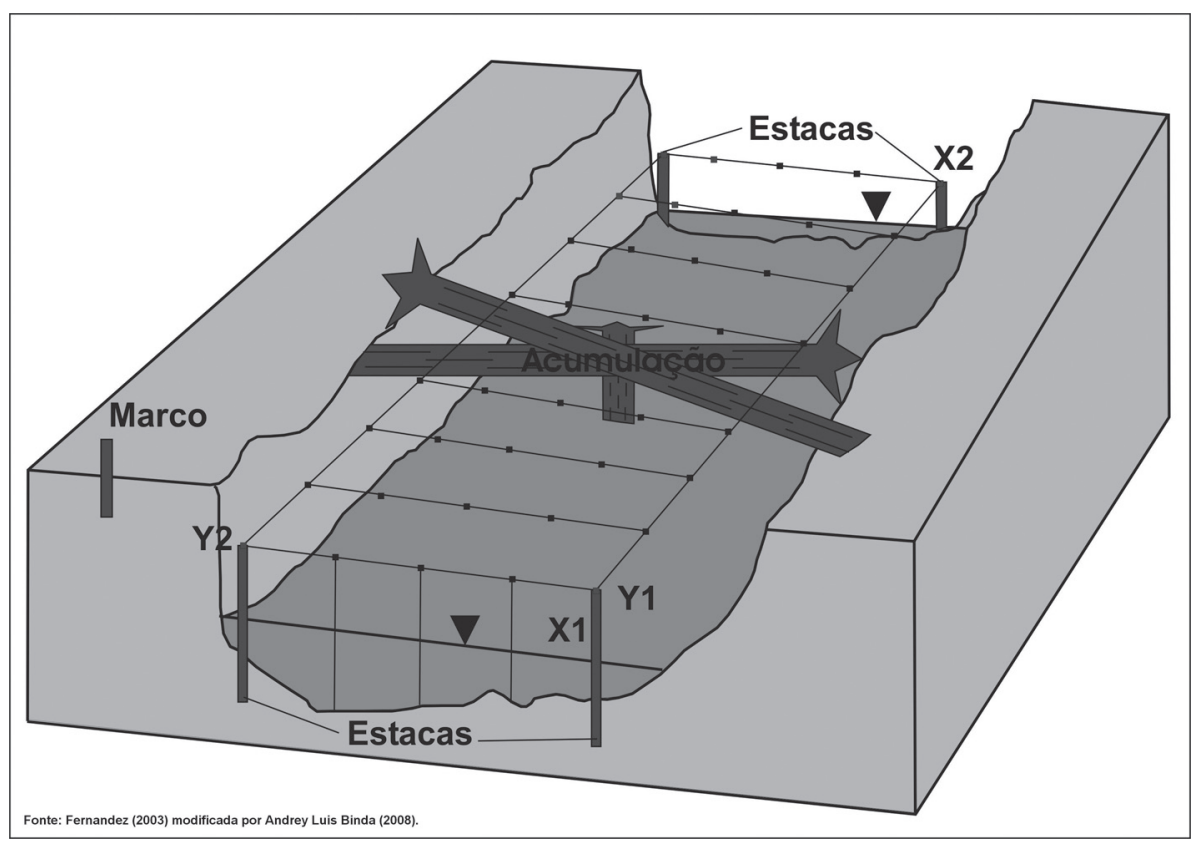

Figura 1 - Levantamento da batimetria do canal ao entorno da acumulação de detritos lenhosos.

Fonte: Fernandez (2003) modificada Binda (2009a).

O valor da cota do leito do canal foi calculado a partir de um marco com nível arbitrário de $100 \mathrm{~m}$ instalado na margem do canal em local que não estivesse sendo afetado por processos fluviais, tais como erosão ou deposição de sedimentos (HARRELSON et alii, 1994; FERNANDEZ et alii, 2001). Em todas as campanhas de campo definia-se o nível da lâmina de água com o emprego de um nível de mangueira. Sabendo-se a cota da lâmina de água, a cota do leito foi calculada subtraindo os valores de profundidade de cada ponto.

No software SPRING (Sistema de Processamento de Informações Georreferenciadas), versão 4.3.3 (INPEC - Instituto Nacional de Pesquisas Espaciais), criou-se uma malha de pontos representativa para cada seção amostrada. Os valores da cota de leito foram calculados para cada ponto medido em campo e inseridos no programa como valor de z. Após a inserção de todos os pontos, o plano de informação foi exportado no formato shapefile e importado para o módulo ArcScene do software Arcgis, versão 9.1 (ESRIC - Environmental Systems Research Institute), onde foi realizada a modelagem 3D para cada seção. Os parâmetros estatísticos aplicados nas seções de monitoramento batimétrico foram obtidos pela função área e volume do menu $3 D$ analyst do ArcScene.

\section{Área de estudo}

A bacia hidrográfica do Rio Guabiroba está localizada no município de Guarapuava, mesorregião centro-sul do Estado do Paraná (Figura 2). A área da bacia é de aproximadamente $23,875 \mathrm{~km}^{2}$ e o canal principal apresenta $10,364 \mathrm{~km}$ de extensão, desde sua nascente até a foz no Rio das Pedras (Sistema do Rio Jordão-Iguaçu). O Rio Guabiroba é caracterizado por apresentar leito misto, com trechos rochosos intercalados por segmentos com cobertura aluvial (LIMA \& BINDA, 2008).

A bacia é esculpida na Unidade Básica Inferior da Formação Serra Geral (Grupo São Bento), caracterizada por rochas de natureza básica-intermediária, normalmente basaltos toleíticos, de granulação muito fina a média, hipocristalinos, de coloração cinza escura a negra, maciços ou vesiculares/amigdaloides e acamamento ígneo mal desenvolvido (NARDY et alii, 2002). Segundo Lima (1999), são encontrados, ao longo do curso fluvial, depósitos aluvionares inconsolidados associados a trechos com baixa declividade, que permitem o desenvolvimento de estreitas planícies de inundação interdigitadas lateralmente com depósitos coluvionares. 


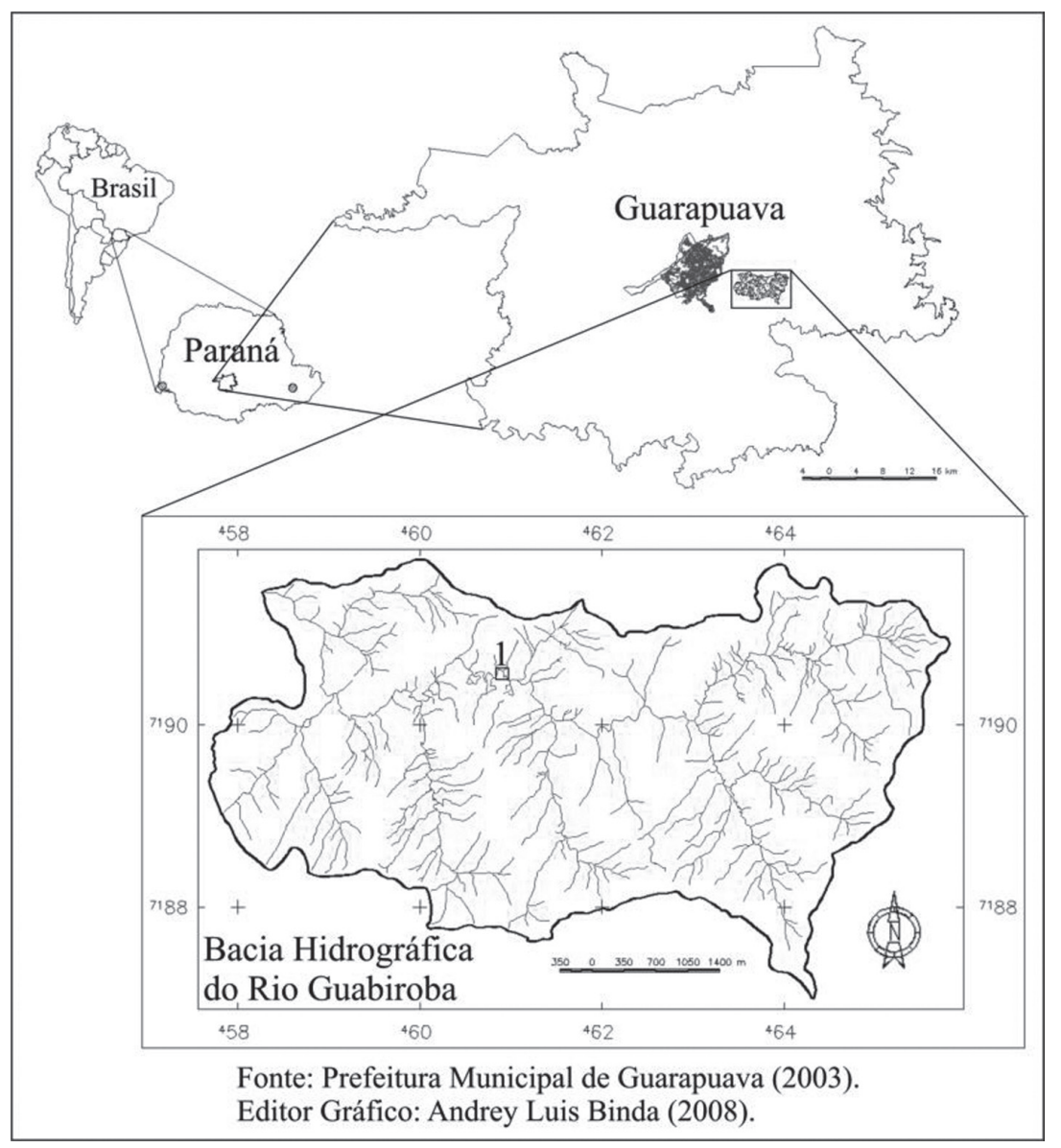

Figura 2 - Localização da bacia do Rio Guabiroba, Guarapuava/PR. Em destaque o trecho em estudo.

O clima do município de Guarapuava, segundo Maack (1981), pertence à zona de clima quente temperado subtropical fresco até frio no inverno. Na classificação de Koeppen, é caracterizado como $\mathrm{Cfb}$, ou seja, zona temperada, sempre úmida com mais de cinco geadas por ano (MAACK, 1981).

A pluviosidade média anual para o período 1954-2006 é de $1821,41 \mathrm{~mm}$. Quanto à distribuição das chuvas ao longo do ano, se destacam os meses de janeiro (192mm) e outubro $(185 \mathrm{~mm})$ como os mais chuvosos e, abril $(129,2 \mathrm{~mm})$ e agosto $(99,5 \mathrm{~mm})$ como os meses menos chuvosos (BINDA, 2009b).

No que tange à paisagem do município, destacam-se os campos limpos (Estepe-gramíneo-lenhosa), capões e matas de galeria associados às florestas de araucárias (Floresta Ombrófila Mista) (MAACK, 1981). Para Behling \& Pillar (2006), esta é uma característica do Sul do Brasil, onde é possível verificar um mosaico formado por campos e florestas de araucária. Na Bacia do Rio Guabiroba, 14,8\% da área são ocupados por florestas, enquanto $59,5 \%$ correspondem a capoeiras, $18 \%$ a pastagens e o restante é vinculado a diferentes usos (LEITÃ0, 1995 apud LIMA, 1999).

\section{Resultados e discussões}

O trecho em estudo localiza-se há 4,9km da Foz do Rio Guabiroba e tem aproximadamente $350 \mathrm{~m}$ de extensão. O índice de sinuosidade é de 1,9 e a declividade da lâmina d'água é de $0,0027 \mathrm{~m} / \mathrm{m}$ (Figura 3). Neste trecho, o canal desenvolve cinco inflexões com angularidade próxima a $90^{\circ}$ e os principais habitats aquáticos têm íntima relação com a feição morfológica do canal, sendo representados por sequências de soleira-depressão. Binda \& Fernandez (2010) mencionam ainda que ocorrem ao longo deste trecho soleiras e depressões forçadas por acumulações de detritos lenhosos. 
No presente trabalho foram monitoradas três seções, cada qual representada por acumulações de detritos lenhosos arranjadas distintamente, conforme descrição a seguir.

A seção 1 (Foto - Figura 3) ocorre sobre uma soleira, onde um grande detrito autóctone, com aproximadamente $0,86 \mathrm{~m}$ de perímetro, prolonga-se transversalmente, ultrapassando o nível de margens plenas, estando em contato com o leito por cerca de $2 \mathrm{~m}$ da margem direita ao centro do canal.
A seção 2 (Foto - Figura 3) encontra-se entre duas inflexões, em ambiente formado por depressão na margem côncava associada à barra em pontal na margem convexa. É formada por quatro membros-chave, sendo dois deles cepos de árvores que caíram e foram posteriormente removidas pelos proprietários da área. Dois membros-chave são os principais formadores da acumulação, sendo um de aproximadamente $3 \mathrm{~m}$ de comprimento e perímetro de $1,10 \mathrm{~m}$, orientado paralelo ao canal, e outro formado por detrito autóctone de $2 \mathrm{~m}$ de comprimento e $0,55 \mathrm{~m}$ de perímetro, situado transversal ao canal.

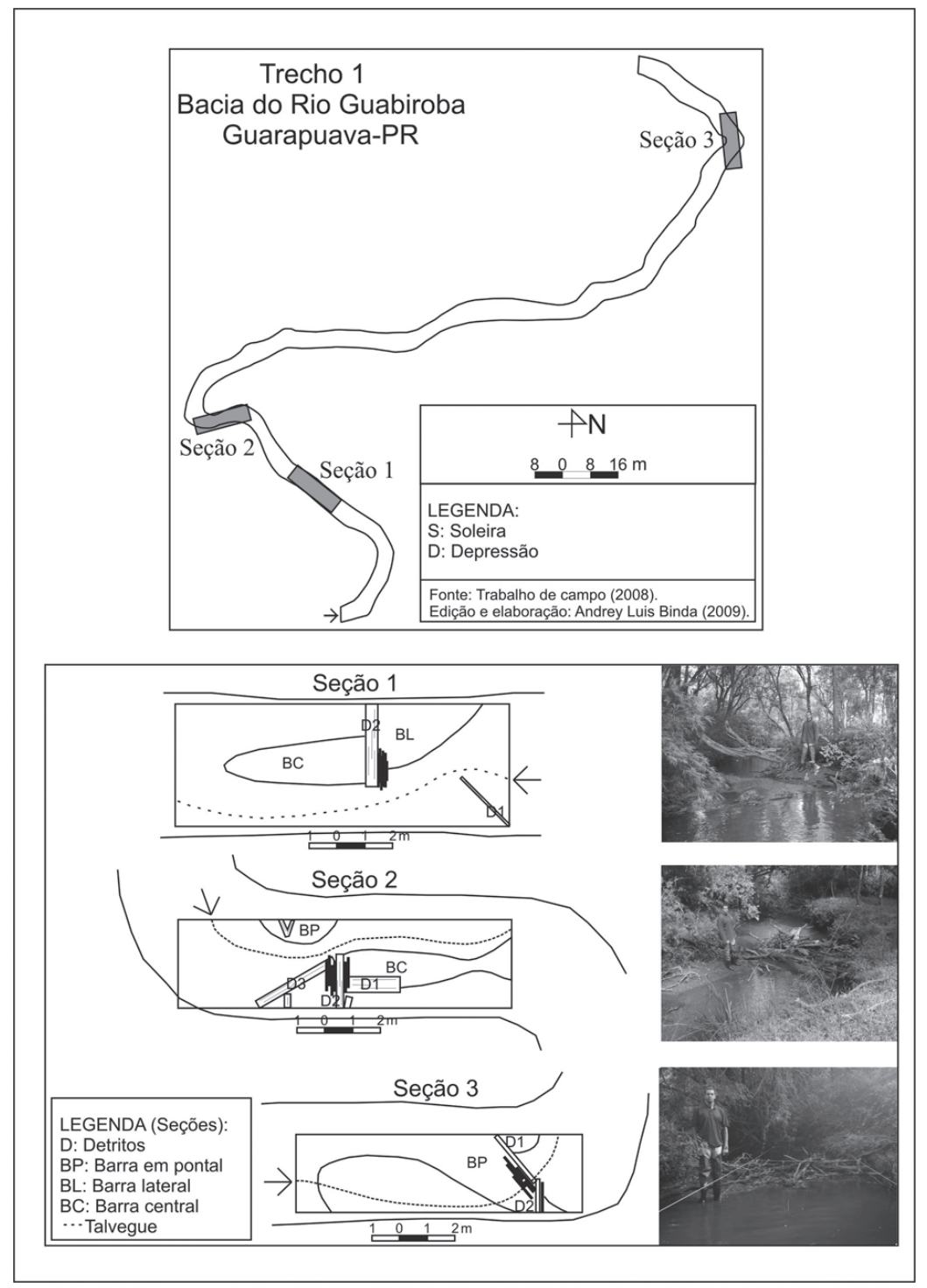

Figura 3 - Localização e croquis esquemáticos das seções monitoradas no trecho estudado. As fotos foram obtidas com vista para jusante. 
A seção 3 (Foto - Figura 3) está localizada em ponto de inflexão, em sistema formado por associação de depressão na margem côncava e sedimentação de barras em pontal na margem convexa. A acumulação é formada por vários pequenos detritos lenhosos, sendo os membros-chave formados por dois troncos, um aderido à margem esquerda com $1 \mathrm{~m}$ de comprimento e $0,43 \mathrm{de}$ perímetro e outro com $2 \mathrm{~m}$ de comprimento e perímetro de $0,50 \mathrm{~m}$. Ambos estão orientados transversalmente ao canal.
Durante o período de monitoramento foram realizados cinco levantamentos batimétricos (17-18 de dezembro de 2007, 17-18 de março de 2008, 8-9 de julho de 2008, 14-17 de novembro de 2008 e 13-15 de março de 2009). Durante esse período, a precipitação acumulada alcançou $1457,8 \mathrm{~mm}$. A distribuição das chuvas apresentou-se variável, com os maiores índices ocorrendo no período entre a terceira e a quarta campanha. Isso fica claro com a relação tempo versus precipitação, na qual os valores das demais campanhas encontraram-se entre 2,65 e 2,74, enquanto foi de 4,48 no período em questão (Tabela 1).

Tabela 1 - Caracterização pluviométrica entre as campanhas de campo.

\begin{tabular}{|c|c|c|c|c|c|c|}
\hline Campanhas & Período & $\begin{array}{c}\text { Precipitação } \\
\text { acumulada } \\
\text { (mm) } P\end{array}$ & $\begin{array}{l}\text { Chuva máxima } \\
24 \text { horas (mm) }\end{array}$ & $\begin{array}{c}\text { Tempo } \\
\text { transcorrido } \\
\text { (dias) } T\end{array}$ & $\begin{array}{l}\text { Dias } \\
\text { com } \\
\text { chuva }\end{array}$ & $\begin{array}{c}\text { Relação } \\
P / T\end{array}$ \\
\hline $\begin{array}{c}1^{\mathrm{a}}-2^{\mathrm{a}} \\
\text { Campanha }\end{array}$ & $\begin{array}{c}18 / 12 / 2007 \mathrm{a} \\
17 / 3 / 2008 \\
\end{array}$ & 246,0 & 28,0 & 91 & 27 & 2,70 \\
\hline $\begin{array}{c}2^{\mathrm{a}}-3^{\mathrm{a}} \\
\text { Campanha }\end{array}$ & $\begin{array}{c}18 / 03 / 2008 \mathrm{a} \\
8 / 7 / 2008\end{array}$ & 300,0 & 30,0 & 113 & 28 & 2,65 \\
\hline $\begin{array}{c}3^{\mathrm{a}}-4^{\mathrm{a}} \\
\text { Campanha }\end{array}$ & $\begin{array}{l}9 / 7 / 2008 \mathrm{a} \\
14 / 11 / 2008\end{array}$ & 577,5 & 65,0 & 129 & 35 & 4,48 \\
\hline $\begin{array}{c}4^{\mathrm{a}}-5^{\mathrm{a}} \\
\text { Campanha }\end{array}$ & $\begin{array}{c}17 / 11 / 2008 \mathrm{a} \\
14 / 3 / 2009\end{array}$ & 334,3 & 26,0 & 122 & 42 & 2,74 \\
\hline
\end{tabular}

Fonte: Grupo de Pesquisa "Monitoramento, experimentação e modelagem em hidrogeomorfologia" (2007-2009). Dados trabalhados por Binda (2009a).

Entretanto, no período entre a terceira e a quarta campanha ocorreram também os maiores valores diários de precipitação, alcançando o máximo de $65 \mathrm{~mm} / 24 \mathrm{~h}$ e acumulado em dois dias de $122 \mathrm{~mm}$. Nas demais campanhas, as chuvas máximas em 24 horas alcançaram no máximo $30 \mathrm{~mm}$ (Tabela 2).

\section{Análise tridimensional dos processos erosivo-de- posicionais associados às acumulações de detritos lenhosos}

\section{Seção 1}

A seção 1 foi caracterizada pela ocorrência de processos de sedimentação na segunda campanha e por processos de erosão nas demais campanhas. Ao final do monitoramento foi possível perceber, por meio da comparação entre os resultados obtidos na primeira e na quinta campanha, que os processos de erosão foram predominantes. Isso conduziu para significativas mudanças, sobretudo nas cotas mínima e média, com redução em $0,14 \mathrm{~m}$ e $0,20 \mathrm{~m}$, respectivamente. Embora $\mathrm{a}$ área superficial tenha apresentado aumento em $1,17 \mathrm{~m}^{2}$, o que demonstra maior variação nas cotas do leito, o volume reduziu em 9,94m³ (Tabela 2; Figura 4).

\section{Seção 2}

Ao comparar os dados morfológicos obtidos nas cinco campanhas, foi possível observar a ocorrência de períodos de sedimentação e de erosão, com a predominância deste último processo. Com exceção da cota máxima, que foi de $98,91 \mathrm{~m}$, as cotas mínima e média reduziram em 0,04 e $0,06 \mathrm{~m}$. Do mesmo modo, a área superficial e o volume apresentaram redução em 0,47 e $2,08 \mathrm{~m}^{3}$, respectivamente (Tabela 3; Figura 5).

\section{Seção 3}

Na seção 3, os processos de erosão foram predominantes em três dos quatro comparativos. Assim, a comparação entre os resultados obtidos na primeira e na quinta campanha confirma a ocorrência dos processos de erosão. Embora a cota máxima tenha aumentado em $0,08 \mathrm{~m}$, as cotas mínima e média reduziram 0,08 e $0,04 \mathrm{~m}$, respectivamente. A área superficial reduziu em $0,48 \mathrm{~m}^{2}$, tornando o leito mais homogêneo, enquanto o volume reduziu em $0,96 \mathrm{~m}^{3}$ (Tabela 4; Figura 6). 
Tabela 2 - Características erosivo-deposicionais da Seção 1.

\begin{tabular}{|c|c|c|c|c|c|c|c|c|}
\hline \multirow[t]{2}{*}{ Campanha } & \multicolumn{4}{|c|}{ Cota (m) } & \multirow{2}{*}{$\begin{array}{l}N^{o} \text { de } \\
\text { pontos }\end{array}$} & \multirow{2}{*}{$\begin{array}{c}\text { Área } \\
\text { superficial }\left(m^{2}\right)\end{array}$} & \multirow{2}{*}{$\begin{array}{l}\text { Volume } \\
\left(m^{3}\right)^{*}\end{array}$} & \multirow{2}{*}{$\begin{array}{c}\text { Processo } \\
\text { predominante }\end{array}$} \\
\hline & Máxima & Minima & Média & D.P. & & & & \\
\hline $\begin{array}{c}1^{a} \text { Campanha } \\
17 / 12 / 2007\end{array}$ & 98,91 & 98,25 & 98,61 & 0,137 & 1113 & 48,27 & 28,99 & --------- \\
\hline $\begin{array}{c}2^{\mathrm{a}} \text { Campanha } \\
17 / 3 / 2008\end{array}$ & 98,94 & 98,30 & 98,62 & 0,131 & 1113 & 48,22 & 29,11 & Deposição \\
\hline Diferença & 0,03 & 0,05 & 0,01 & -1---- & ------- & $-0,05$ & 0,12 & -------- \\
\hline $\begin{array}{c}3^{\mathrm{a}} \text { Campanha } \\
8 / 7 / 2008\end{array}$ & 98,89 & 98,22 & 98,58 & 0,124 & 1113 & 48,27 & 27,38 & Erosão \\
\hline Diferença & $-0,05$ & $-0,08$ & $-0,04$ & -------- & ------- & 0,05 & $-1,73$ & --------- \\
\hline $\begin{array}{l}4^{a} \text { Campanha } \\
14 / 11 / 2008\end{array}$ & 98,88 & 98,16 & 98,42 & 0,128 & 1113 & 50,00 & 19,58 & Erosão \\
\hline Diferença & $-0,01$ & $-0,06$ & $-0,16$ & --------- & -------- & 1,73 & $-7,80$ & ---------- \\
\hline $\begin{array}{c}5^{\text {a Campanha }} \\
13 / 3 / 2009\end{array}$ & 98,91 & 98,11 & 98,41 & 0,124 & 1113 & 49,44 & 19,05 & Erosão \\
\hline Diferença & 0,03 & $-0,05$ & $-0,01$ & -------- & -------- & $-0,56$ & $-0,53$ & --------- \\
\hline $\begin{array}{c}\text { Diferença } \\
1^{\mathrm{a}}-5^{\mathrm{a}} \text { Campanha }\end{array}$ & 0,00 & $-0,14$ & $-0,20$ & --------- & ------- & 1,17 & $-9,94$ & Erosão \\
\hline
\end{tabular}

*Cota de referência: $98,00 m$.

D.P.: Desvio padrão

Fonte: Dados de campo (2007-2009). Organização: Binda (2009a).

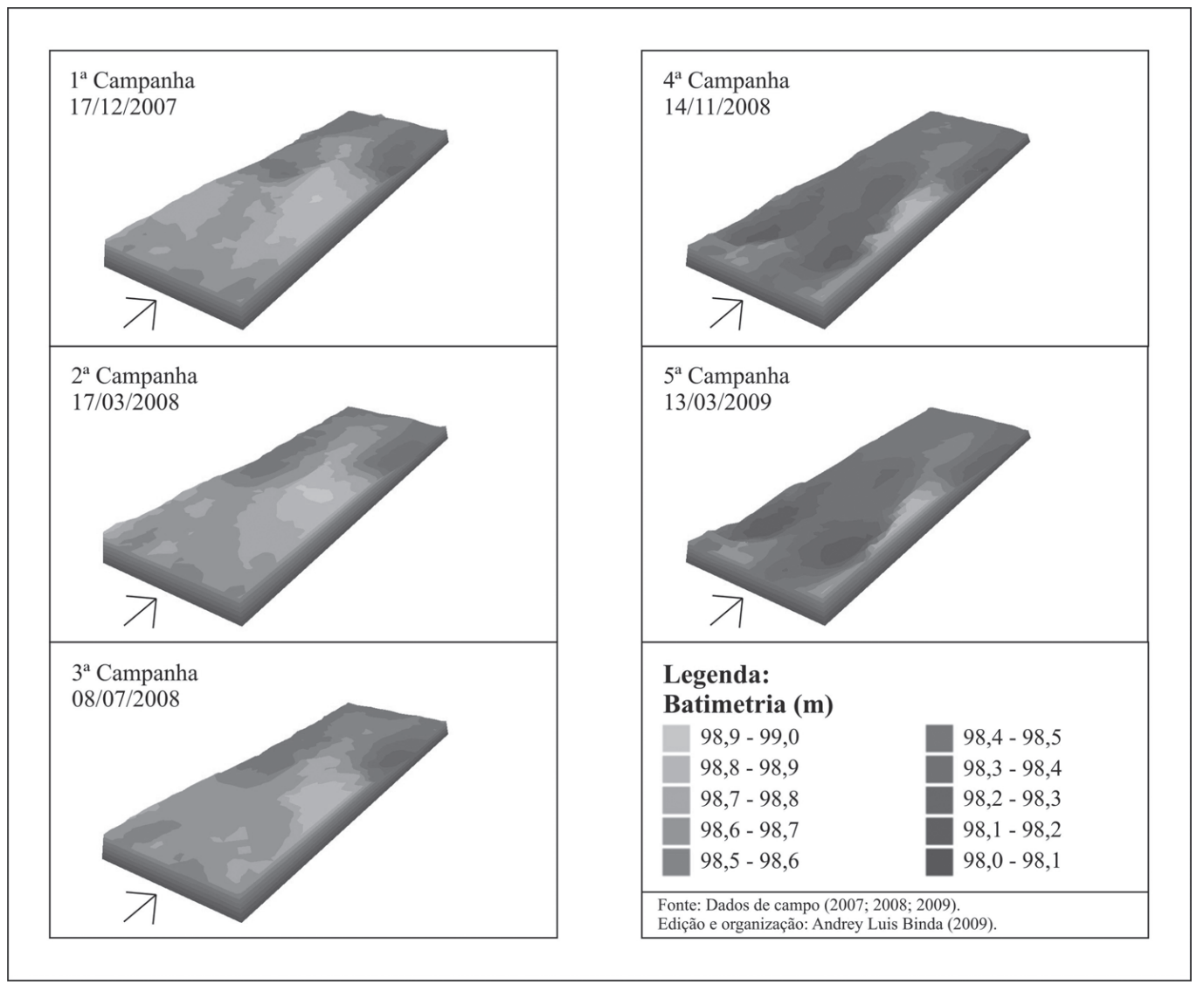

Figura 4 - Modelos 3D da seção 1. 
Binda, A. L. \& Fernandez, O. V. Q.

Tabela 3 - Características erosivo-deposicionais da Seção 2.

\begin{tabular}{|c|c|c|c|c|c|c|c|c|}
\hline \multirow[t]{2}{*}{ Campanha } & \multicolumn{4}{|c|}{ Cota (m) } & \multirow{2}{*}{$\begin{array}{l}N^{o} \text { de } \\
\text { pontos }\end{array}$} & \multirow{2}{*}{$\begin{array}{c}\text { Área } \\
\text { superficial }\left(m^{2}\right)\end{array}$} & \multirow{2}{*}{$\begin{array}{l}\text { Volume } \\
\left(\mathrm{m}^{3}\right)^{*}\end{array}$} & \multirow{2}{*}{$\begin{array}{c}\text { Processo } \\
\text { predominante }\end{array}$} \\
\hline & Máxima & Minima & Média & D.P. & & & & \\
\hline $\begin{array}{l}1^{\text {a }} \text { Campanha } \\
17 / 12 / 2007\end{array}$ & 98,91 & 97,89 & 98,31 & 0,198 & 918 & 40,53 & 26,37 & ---------- \\
\hline $\begin{array}{c}2^{\mathrm{a}} \text { Campanha } \\
17 / 3 / 2008\end{array}$ & 98,87 & 97,96 & 98,34 & 0,180 & 918 & 40,47 & 27,49 & Deposição \\
\hline Diferença & $-0,04$ & 0,07 & 0,03 & --------- & ------- & $-0,06$ & 1,12 & ---------- \\
\hline $\begin{array}{c}3^{\mathrm{a}} \text { Campanha } \\
8 / 7 / 2008\end{array}$ & 98,89 & 97,92 & 98,26 & 0,187 & 918 & 40,95 & 24,49 & Erosão \\
\hline Diferença & 0,02 & $-0,04$ & $-0,08$ & --------- & -------- & 0,48 & $-3,00$ & ---------- \\
\hline $\begin{array}{c}4^{\mathrm{a}} \text { Campanha } \\
14 / 11 / 2008\end{array}$ & 98,88 & 97,63 & 98,22 & 0,229 & 918 & 40,36 & 23,07 & Erosão \\
\hline Diferença & $-0,01$ & $-0,29$ & $-0,04$ & --------- & -------- & $-0,59$ & $-1,42$ & ----------- \\
\hline $\begin{array}{c}5^{\mathrm{a}} \text { Campanha } \\
14 / 3 / 2009\end{array}$ & 98,91 & 97,85 & 98,25 & 0,196 & 918 & 40,06 & 24,29 & Deposição \\
\hline Diferença & 0,03 & 0,22 & 0,03 & --------- & -------- & $-0,30$ & 1,22 & ---------- \\
\hline $\begin{array}{c}\text { Diferença } \\
1^{\mathrm{a}}-5^{\mathrm{a}} \text { Campanha }\end{array}$ & 0,00 & $-0,04$ & $-0,06$ & --------- & -------- & $-0,47$ & $-2,08$ & Erosão \\
\hline
\end{tabular}

*Cota de referência: 97,60m. D.P.: Desvio padrão

Fonte: Dados de campo (2007-2009). Organização: Binda (2009a).

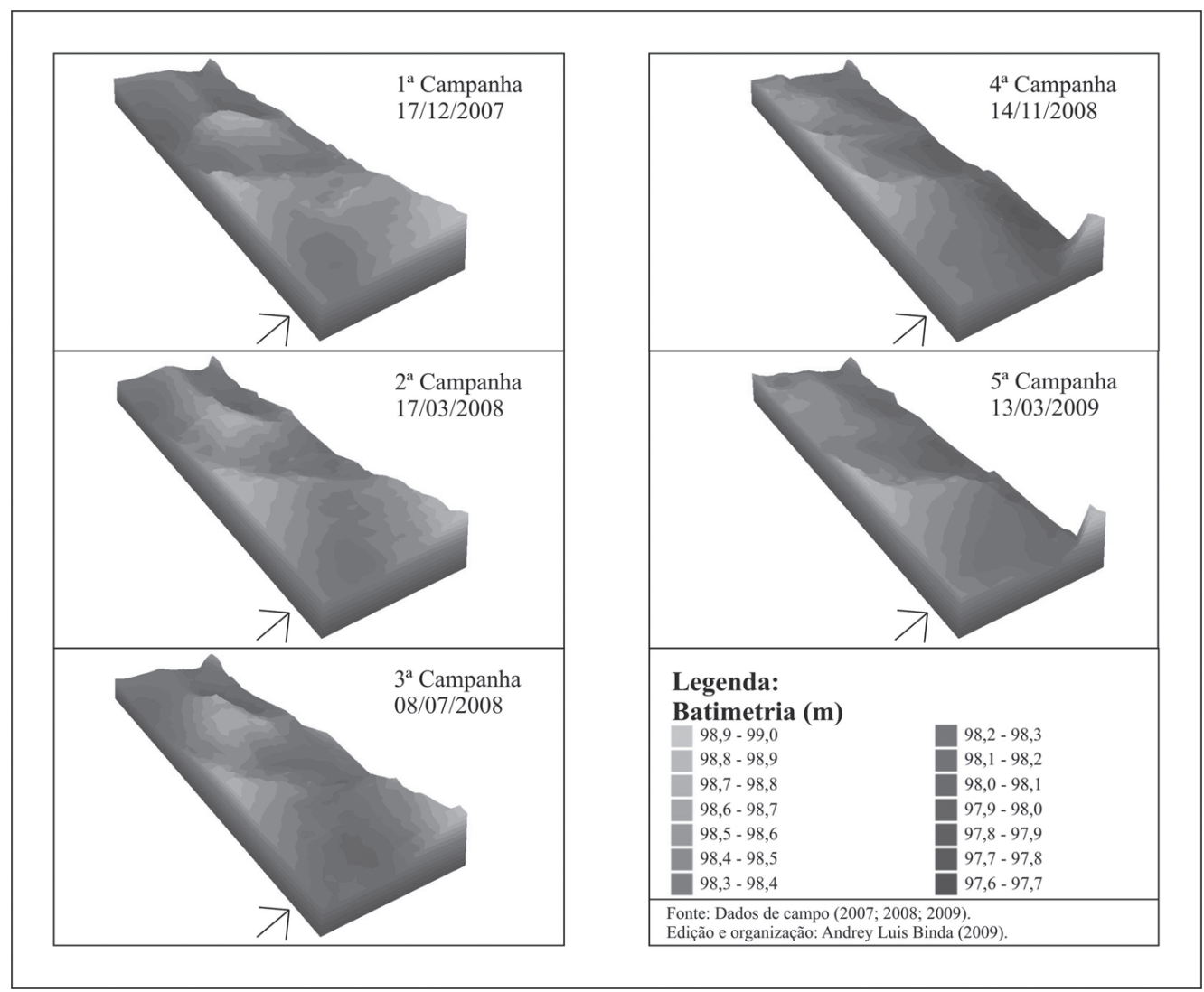

Figura 5 - Modelos 3D da seção 2. 
Tabela 4 - Características erosivo-deposicionais da Seção 3.

\begin{tabular}{|c|c|c|c|c|c|c|c|c|}
\hline \multirow[t]{2}{*}{ Campanha } & \multicolumn{4}{|c|}{ Cota (m) } & \multirow{2}{*}{$\begin{array}{l}N^{o} \text { de } \\
\text { pontos }\end{array}$} & \multirow{2}{*}{$\begin{array}{c}\text { Área } \\
\text { superficial }\left(m^{2}\right)\end{array}$} & \multirow{2}{*}{$\begin{array}{l}\text { Volume } \\
\left(m^{3}\right)^{*}\end{array}$} & \multirow{2}{*}{$\begin{array}{c}\text { Processo } \\
\text { predominante }\end{array}$} \\
\hline & Máxima & Minima & Média & D.P. & & & & \\
\hline $\begin{array}{c}1^{\text {a }} \text { Campanha } \\
17 / 12 / 2007\end{array}$ & 98,91 & 97,89 & 98,31 & 0,198 & 918 & 40,53 & 26,37 & ------- \\
\hline $\begin{array}{c}2^{\mathrm{a}} \text { Campanha } \\
17 / 3 / 2008\end{array}$ & 98,87 & 97,96 & 98,34 & 0,180 & 918 & 40,47 & 27,49 & Deposição \\
\hline Diferença & $-0,04$ & 0,07 & 0,03 & -------- & ------- & $-0,06$ & 1,12 & --------- \\
\hline $\begin{array}{c}3^{\text {a }} \text { Campanha } \\
8 / 7 / 2008\end{array}$ & 98,89 & 97,92 & 98,26 & 0,187 & 918 & 40,95 & 24,49 & Erosão \\
\hline Diferença & 0,02 & $-0,04$ & $-0,08$ & ------- & ------- & 0,48 & $-3,00$ & -------- \\
\hline $\begin{array}{c}4^{\mathrm{a}} \text { Campanha } \\
14 / 11 / 2008\end{array}$ & 98,88 & 97,63 & 98,22 & 0,229 & 918 & 40,36 & 23,07 & Erosão \\
\hline Diferença & $-0,01$ & $-0,29$ & $-0,04$ & -------- & -------- & $-0,59$ & $-1,42$ & ---------- \\
\hline $\begin{array}{c}5^{\text {a }} \text { Campanha } \\
14 / 3 / 2009\end{array}$ & 98,91 & 97,85 & 98,25 & 0,196 & 918 & 40,06 & 24,29 & Deposição \\
\hline Diferença & 0,03 & 0,22 & 0,03 & --------- & ------- & $-0,30$ & 1,22 & -------- \\
\hline $\begin{array}{c}\text { Diferença } \\
1^{\mathrm{a}}-5^{\mathrm{a}} \text { Campanha }\end{array}$ & 0,00 & $-0,04$ & $-0,06$ & -------- & ------- & $-0,47$ & $-2,08$ & Erosão \\
\hline
\end{tabular}

*Cota de referência: $97,90 m$.

D.P.: Desvio padrão

Fonte: Dados de campo (2007-2009). Organização: Binda (2009a).

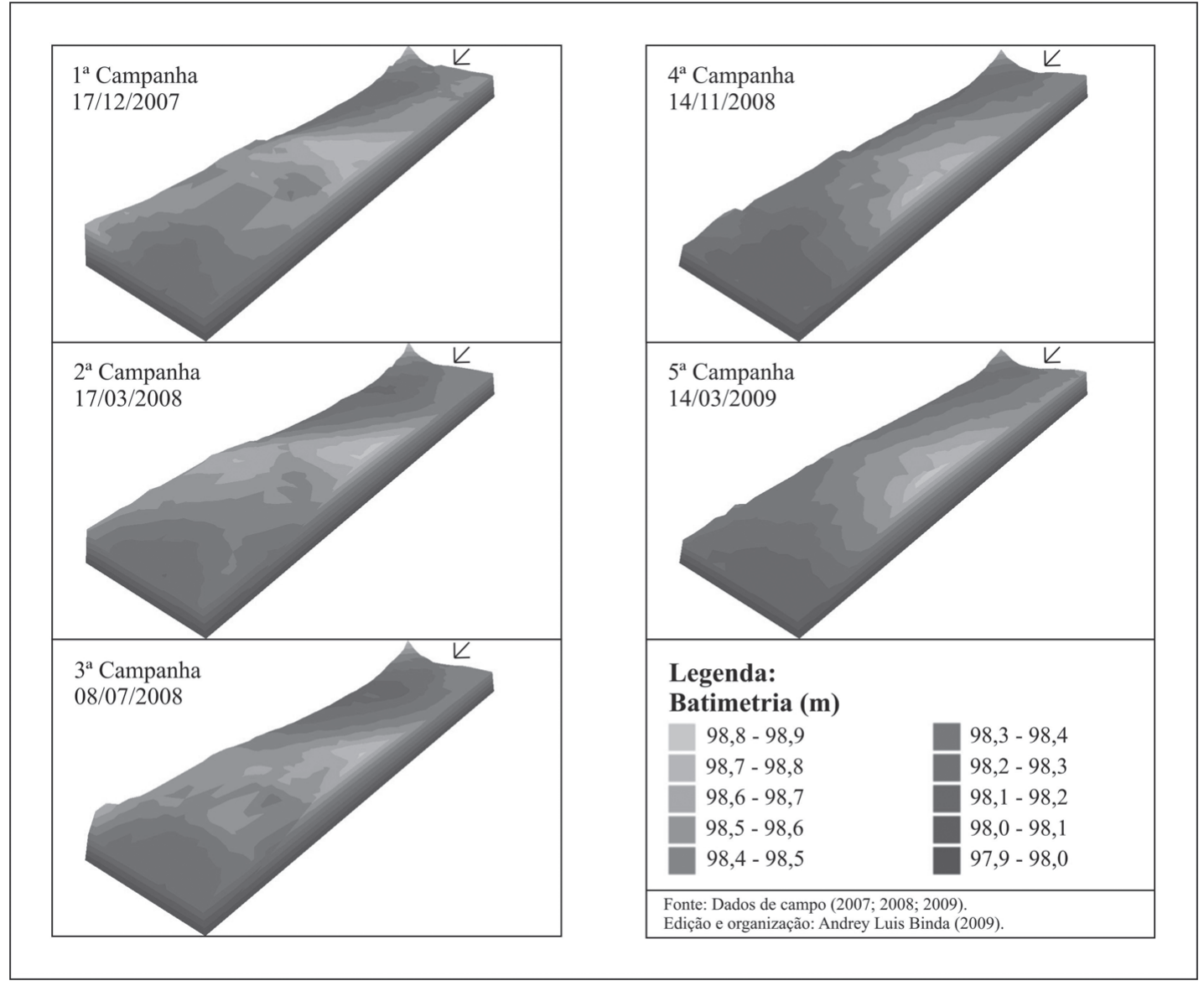

Figura 6 - Modelos 3D da seção 3. 


\section{Considerações finais}

A esculturação de canais afetados pela presença de detritos lenhosos depende, principalmente, de dois fatores: 1) da existência de uma acumulação que seja suficientemente expressiva de modo a alterar a rugosidade do canal e 2) de fluxos que sejam fortes o suficiente para permitir a remobilização do material de leito. A presença dos troncos permite a geração de fluxos com magnitudes diferentes de tensão de cisalhamento que ensejam processos de erosão ou de sedimentação em diferentes partes do canal.

Isso é claro quando é comparada a efetividade dos processos erosivo-deposicionais durante o período de monitoramento com o regime pluviométrico. Os dados das seções de monitoramento batimétrico indicam a ocorrência de dois importantes períodos deposicionais na segunda campanha (exceto na Seção 3) e quinta campanha (exceto na Seção 1). Ambos períodos foram representados por baixa precipitação, que alcançou acumulado de $246 \mathrm{~mm}$ e $334,3 \mathrm{~mm}$, respectivamente, com máxima em 24 horas de $28 \mathrm{~mm}$ e $26 \mathrm{~mm}$. Esses baixos valores de precipitação estiveram propiciando a deposição de sedimentos no leito, elevando a cota do talvegue.

Com isso, é possível esboçar uma síntese relacionando o regime pluviométrico com a efetividade dos processos erosivo-deposicionais. A ocorrência de eventos extremos de precipitação e sua relação com altos fluxos demonstram o papel geomorfológico das vazões de margens plenas na esculturação de canais fluviais, tal como afirmam Leopold et alii (1964) e Baker \& Kale (1998).

Foi, entretanto, possível encontrar diferentes taxas de erosão e de deposição nos períodos entre campanhas. Se por um lado a maior taxa de erosão na Seção 1 esteve vinculada com a quarta campanha, nas outras seções foi possível perceber campanhas com efetividade até mesmo maior do que da quarta campanha. Isso vem a reforçar a noção de complementaridade entre diferentes vazões no trabalho de esculturação de canais, sobretudo de canais mistos (aluvial-rochoso) (HARTSHORN et alii, 2002; LAGUE et alii, 2005).

Outro ponto a ser considerado é que, tal como afirmam Faria (2000); Curran \& Wohl (2003) e Faustini \& Jones (2003), a resistência ao fluxo, originada por acumulações de detritos lenhosos, tende a diminuir em função do aumento da descarga, quando esses elementos se tornam pequenos em relação à profundidade. Assim, a influência dos detritos lenhosos nos processos erosivodeposicionais de canais fluviais tende a ser maior durante as descargas que cobrem as acumulações.

\section{Referências bibliográficas}

BAKER, V. R.; KALE, V. S. The role of extreme floods in shaping bedrock channels. In: TINKLER, K. J.; WOHL, E. E. Rivers over rock: fluvial processes in bedrock channels. American Geophysical Union: Washington-DC, 1998., p. $1-18$.

BEHLING, H \& PILLAR, V. D. Late quaternary vegetation, biodiversity and fire dynamics on the southern Brasilian highland and their implication for conservation and management of modern Araucaria forest and grassland ecosystems. Philosophical Transactions of The Royal Society, v.362, 2006., p. 243-251.

BINDA, A. L. A influência de detritos lenhosos na morfologia e na sedimentologia de leito no Rio Guabiroba, GuarapuavaPR. Dissertação de mestrado. Francisco Beltrão: Programa de Pós-graduação em Geografia, 2009a., 120p.

BINDA, A. L. Regime pluviométrico e vazões extremas no Rio das Pedras, Guarapuava/PR. In: IV Simpósio Paranaense de Pós-graduação em Geografia. Marechal Cândido Rondon/PR: UNIOESTE, 2009b.

BINDA, A. L. \& FERNANDEZ, O. V. Q. Detritos lenhosos e sequência de soleiras e depressões no Rio Guabiroba, Guarapuava/PR. Geografia, v.35, n. 2. Rio Claro: Unesp, 2010, p. 411-422.

BRUMMER, C. J.; ABBE, T. B.; SAMPSON, J. R.; MONTGOMERY, D. R. Influence of vertical channel change associated with wood accumulations on delineating channel migration zones, Washington, USA. Geomorphology, n. 80, 2006, p. 295-309.

CHRISTOFOLETTI, A. Geomorfologia fluvial. São Paulo: Edgard Blücher, 1981.

CURRAN, J. H. \& WOHL, E. E. Large woody debris and flow resistance in step-pool channels, Cascade Range, Washington. Geomorphology, n. 51, 2003, p. 141-157.

DOWNS, P. W. \& SIMON, A. Fluvial geomorphological analysis of the recruitment of large woody debris in the Yalobusha River network, Central Mississipi, USA. Geomorphology, n. 37, 2001, p. 65-91.

FARIA, A.P. Influência da vegetação nos processos fluviais de bacias de primeira ordem. Revista Brasileira de Recursos Hídricos, v.5, n.3, p. 50-68, 2000.

FAUSTINI, J. M. \& JONES, J. A. Influence of large woody debris on channel morphology and dynamics in steep, boulder-rich mountain streams, western Cascades, Oregon. Geomorphology, n. 51, 2003, p. 187-205.

FERNANDEZ, O. V. Q.; REBELATTO, G. E.; SANDER, C. Análise quantitativa de seções transversais em pequenos canais fluviais. Revista Brasileira de Geomorfologia. v. 2, $\mathrm{n}^{\mathrm{o}} 1,2001$. 
FERNANDEZ, O. V. Q. Mudanças topográficas e sedimentológicas em uma unidade soleira-depressão no Córrego Guavirá, Marechal Cândido Rondon, Paraná. Pesquisas em Geociências. n. 30 (1), 2003, p. 53-63.

HARRELSON, C. C.; RAWLINS, C. L.; POTYONDY, J. P. Stream channel reference sites: an illustrated guide of field technique. Gen. Tech. Rep. RM-245. Fort Collins, CO: U.S. Department of Agriculture, Forest Service, Rocky Mountain Forest and Range Experiment Station, 1994.

HARTSHORN, K.; HOVIUS, N.; DADE, W. B.; SLINGERLAND, R. L. Climate-driven bedrock incision in an active mountain belt. Science, 297, 2002, p. 2036-2038.

KELLER, E. A. \& SWANSON, F. J. Effects of large organic material on channel form and fluvial processes. Earth Surface Processes, v. 4, 1979, p. 361-380.

LAGUE, D.; HOVIUS, N.; DAVY, P. Discharge, discharge variability, and the bedrock channel profile. J. Geophys. Res., 110, F04006, doi:10.1029/2004JF000259, 2005.

LEOPOLD, L. B.; WOLMAN, M. G.; MILLER, J. P. Fluvial processes in Geomorphology. San Francisco: Freeman and Co., 1964, 522p.

LIMA, A.G. Avaliação do controle geológico-estrutural no comportamento da rede de drenagem do Rio das Pedras, Guarapuava/PR. Dissertação de Mestrado. Rio Claro: IGCE/ UNESP, 1999, p.142.

LIMA, A. G. \& BINDA, A. L. Vazão de margens plenas em canal misto rochoso-aluvial: um teste preliminar de equações empíricas. In: VII Simpósio Nacional de GeomorfologiaSINAGEO; II Encontro Latino-americano de Geomorfologia. Belo Horizonte: UFMG, 2008, cd-rom.

LIMA, W. P. \& ZAKIA, M. J. B. Hidrologia de matas ciliares. In: RODRIGUES, R. R. \& LEITÃO FILHO, H. F. Matas ciliares: conservação e recuperação. 2. ed, São Paulo: Editora da Universidade de São Paulo, Fapesp, 2004.
MAACK, R. Geografia física do Estado do Paraná. 2. ed. Rio de Janeiro: J. Olympio; Curitiba: Secretaria da Cultura e do Esporte do Governo do Estado do Paraná, 1981.

MARCUS, W. A.; MARSTON, R. A.; COLVARD JR, C. R.; GRAY, R. D. Mapping the spatial and temporal distributions of woody debris in streams of the Greater Yellowston Esosystem, USA. Geomorphology, n. 44, 2002, p. 323-335.

MONTGOMERY, D. R. \& PIÉGAY, H. Wood in rivers: interactions with channel morphology and processes. Geomorphology, n. 51, 2003, p. 1-5.

MONTGOMERY, D. R. \& ABBE, T. B. Influence of logjamformed hard points on the formation of valley-bottom landforms in an old-growth forest valley, Queets River, Washington, USA. Quaternary Research, n. 65, 2006, p. 147-155.

MUTZ, M.; PIÉGAY, H.; GREGORY, K. J.; BORCHARDT, D.; REICH, M.; SCHMIEDER.K. Perception and evaluation of dead wood in streams and rivers by German students. Limnologica, n. 36, 2006, p.110-118.

NARDY, A. J. R.; OLIVEIRA, M. A. F.; BETANCOURT, R. H. S.; VERDUGO, D. R. H.; MACHADO, F. B. Geologia e estratigrafia da Formação Serra Geral. Geociências. v.21, nº 1/2, São Paulo: UNESP, 2002.

PIÉGAY, H. \& GURNELL, A. M. Large woody debris and river geomorphological pattern: examples from S.E. France e S. England. Geomorphology, n. 19, 1997, p. 99-116.

SUGUIO, K. \& BIGARELlA, J. J. Ambientes fluviais. Florianópolis: UFSC/UFPR, 1990.

WOOSTER, J. \& HILTON, S. Large woody debris volumes e accumulation rates in cleaned streams in Redwood Forest in Sousthern Humboldt County, Califórnia. Oregon: USDA, Forest Services, Pacific Southwest Research Station, 2004.

YOUNG, M. K.; MACE, E.A.;ZIEGLER, E. T.; SUTHERLAND, E. K. Characterizing and contrasting instream and riparian coarse wood in western Montana basins. Forest Ecology and Management, n. 226, 2006, p. 26-40. 